\title{
Doppler reconstruction of left ventricular pressure from functional mitral regurgitation: potential importance of varying orifice geometry
}

\author{
Han B Xiao, Xu Y Jin, Derek G Gibson
}

\begin{abstract}
Objective-To assess the left ventricular pressure pulse, in particular its time course, reconstructed from the continuous wave Doppler signal of functional mitral regurgitation using the simplified Bernoulli equation.

Design-Prospective study with simultaneously recorded high fidelity left ventricular pressure and continuous wave Doppler traces of functional mitral regurgitation, along with indirect left atrial pressure, electrocardiograms, and phonocardiograms.

Setting-Tertiary referral cardiac centre. Patients-9 patients (age 60 (17) years) were studied immediately before or 1-20 h after routine cardiac surgery.
\end{abstract}

Results-104 cardiac cycles were analysed. There were no consistent differences between directly measured and reconstructed pressures in the time intervals from $Q$ to $+\mathrm{dP} / \mathrm{d} t$ (mean (SD) 125 (35) $v 130$ (35) $\mathrm{ms}$ and from $Q$ to $-\mathrm{dPld} t(389$ (30) $v 387$ (28) $\mathrm{ms}$ or from $Q$ to maximum pressure $(267(40) v 270(40)$ $m s$, all $P=N S)$. The time from $Q$ to the onset of pressure rise (67 (30) $v 64$ (30) $\mathrm{ms}, P<0.01)$ and the duration of total left ventricular systole (404 (50) $v 408$ (50) ms, $P<0.01$ ) measured by the two methods were effectively identical, though the small difference was consistent enough to be statistically significant. The calculated peak pressure drop between the left ventricle and the left atrium (45-100 $\mathrm{mm} \mathrm{Hg})$ significantly underestimated left ventricular pressure (72-150 mm Hg; 70 (11) $v 105$ (15) $\mathrm{mm}$ $\mathrm{Hg}, \mathrm{P}<0.01)$ even if mean left atrial pressure $(14(4 \cdot 0) \mathrm{mm} \mathrm{Hg})$ was taken into account. Compared with those directly derived from left ventricular pressure, values of pressure measured at $+\mathrm{d} P / \mathrm{d} t$ (26 (6.5) v 53 (10) $\mathrm{mm} \mathrm{Hg}, P<0.01)$ and $-\mathrm{dP} / \mathrm{d} t(30(8 \cdot 0)$ v 60 (10) $\mathrm{mm} \mathrm{Hg}, \mathrm{P}<$ $0.01)$, and those of the rates of increase (675 (155) $v 815$ (155) $\mathrm{mm} \mathrm{Hg} / \mathrm{s}, \mathrm{P}<0.01)$ and fall (610 (145) $v 845$ (175) $\mathrm{mm} \mathrm{Hg}, P<$ $0.01)$ were all significantly underestimated by Doppler. The underestimation in peak rates of pressure change could not entirely be explained by a scaling effect of absolute pressure. To investigate interrelations between the two methods throughout the cardiac cycle, reconstructed left ventricular pressure was plotted against the direct record. The plots confirmed that the reconstructed pressure was always less than directly measured pressure, the relative degree of underestimation falling as the pressure rose. This was not the effect of acceleration, but probably reflects changing geometry of the regurgitant orifice.

Conclusion-The continuous wave Doppler trace of functional mitral regurgitation is suitable for studying the timing of overall mechanical events and normalised rates of change of pressure in the left ventricle. Estimates of atrioventricular pressure drop by this method and particularly its absolute rates of change seem to be less reliable.

(Br Heart f 1995;73:53-60)

Keywords: mitral regurgitation, Doppler measurement.

The time course of left ventricular pressure has long been used to assess left ventricular mechanical activity. In 1921, Wiggers described the phases of a cardiac cycle using the combination of left ventricular and aortic pressure pulses, ${ }^{1}$ and noted that the time course of left ventricular pressure could be affected by activation pattern. ${ }^{23}$ More recently, the ventricular pressure pulse has been used to time the onset and duration of mechanical systole ${ }^{45}$ and to assess an entity described as "contractility" from its peak rate of change. ${ }^{6}$ Peak left ventricular pressure and its rates of change have been derived both experimentally ${ }^{78}$ and clinically ${ }^{9-11}$ from the continuous wave Doppler trace of mild mitral regurgitation using the simplified Bernoulli equation. However, the time relations of the reconstructed left ventricular pressure pulse have not been systematically investigated. We wished to study this question and also to validate further Doppler-derived left ventricular pressure and its rates of change. We therefore recorded simultaneous records of left ventricular pressure made by high fidelity micromanometer and functional mitral regurgitation signals by continuous wave Doppler to make a detailed comparison of the two.

\section{Patients and methods}

PATIENTS

Nine patients aged from 29 to 80 (60 (17)) years were studied immediately before (one case, number 7 ) or 1-20 h after (eight cases) 
Figure 1 Original traces (A) of left ventricular pressure pulse $(L V P)$ and Doppler signals of functional mitral regurgitation $(M R)$ with electrocardiogram (ECG) and phonocardiogram and phonocardiogram $(B, C)$ with time markers. Zero represents the onset of the $Q R S$ complex. $A 2$ aortic closure.
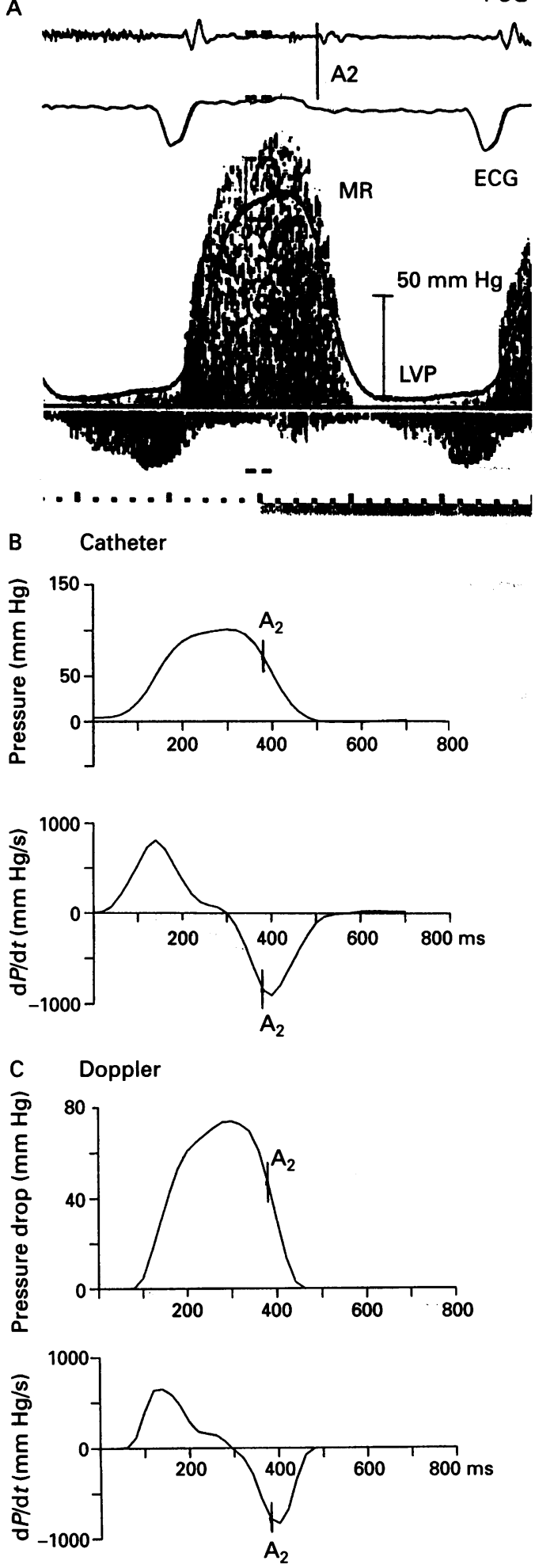

cardiac surgery including aortic valve replacement (six cases) or coronary bypass grafting (one) or both (two). All patients except one with epicardial pacing were in sinus rhythm. The patients were selected only on the quality of the mitral regurgitation trace. No patient had organic mitral valve disease, and in none was mitral regurgitation graded as more than mild. As left ventricular haemodynamics can change significantly in the first $24 \mathrm{~h}$ after operation, ${ }^{12}$ three patients were studied twice postoperatively at an interval of 6-9 h. All the records made in these patients were part of another study of perioperative left ventricular function, which had been approved by the ethics committee of the Royal Brompton Hospital.

\section{LEFT VENTRICULAR PRESSURE}

A 4 French gauge Gaeltec (Isle of Skye) tip pressure catheter with a sensitivity of $5 \mu \mathrm{V} / \mathrm{V} / \mathrm{mm} \mathrm{Hg}$ and a bridge resistance of $2.0 \mathrm{k} \Omega$ were used to record left ventricular pressure. The catheter was introduced into the left ventricle via the right upper pulmonary vein with its tip in the middle portion of the left ventricular cavity during routine cardiac surgery. It remained in situ for $24 \mathrm{~h}$. It was interfaced with the auxiliary amplifier on a Hewlett Packard Sonos 1000 echocardiograph (Andover, MA). The pulmonary wedge pressure recorded by a Swan-Ganz catheter was taken as being equal to mean left atrial pressure or left ventricular end diastolic pressure, allowing the base-line (zero level) to be defined. Pressure calibration was confirmed with an air-operated dead-weight pressure balance (Budenberg Gauge Company Ltd) before and after every insertion.

\section{ECHOCARDIOGRAPHY}

Echocardiograms were recorded by a Hewlett Packard 5.0 $\mathrm{MHz}$ biplane transoesophageal transducer. In a four chamber view, maximum velocity of continuous wave Doppler signals of functional mitral regurgitation were obtained by manipulating the transducer under colour mapping using both planes. The mitral regurgitation signal was recorded simultaneously with left ventricular pressure traces, electrocardiogram, and phonocardiogram at a paper speed of $100 \mathrm{~mm} / \mathrm{s}$ (fig $1 \mathrm{~A}$ ). A wall filter of $1 \mathrm{kHz}$ was used when continuous wave Doppler was recorded. $M$ mode echocardiograms of the left ventricle just at the tip level of the mitral valve were also recorded.

\section{OFF-LINE DIGITISATION}

The left ventricular pressure traces and mitral regurgitation signals were digitised off-line along with the same time calibrations at $20 \mathrm{~ms}$ time intervals. From Doppler signals the pressure drop from the left ventricle to the left atrium and its time course and its rates of change were derived using the simplified Bernoulli equation, $\Delta P=4 \mathrm{~V}^{2}$. From the original traces and the digitised plots, the following measurements were made (figs $1 \mathrm{~B}$ and 1C):

(a) Total systolic time. On Doppler traces this was defined as the overall duration of mitral regurgitation, the onset and termination being defined by direct linear extrapolation, over the frequency range of the $1 \mathrm{kHz}$ filter. On the left ventricular pressure pulse it was measured from the time of rapid onset of the upstroke, after the A wave, to the same level on the downstroke.

(b) Time to onset of mitral regurgitation or left ventricular pressure from the onset of the QRS complex.

(c) Peak left ventricular pressure from the direct record, and peak left ventricle to left 
Figure 2 Theoretical interrelations between directly measured and reconstructed $\left(4 V^{2}\right.$ or $4 V^{2}$ $+L A P)$ left ventricular pressure (LVP). The thin straight line represents the line of identity on each.

(A) Reconstructed pressure is identical with the directly measured pressure throughout systole. (B) The acceleration and deceleration terms of the full Bernoulli equation are important. Arrows indicate the direction in which the loop is inscribed. (C) Viscosity and orifice geometry lead to an asymmetrical relation, with underestimation throughout systole. LAP, left atrial pressure.

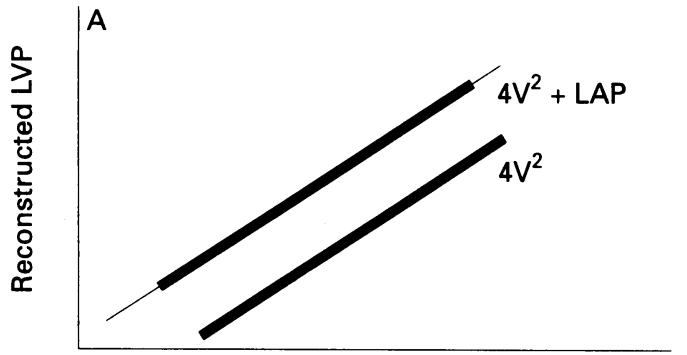

Left ventricular pressure

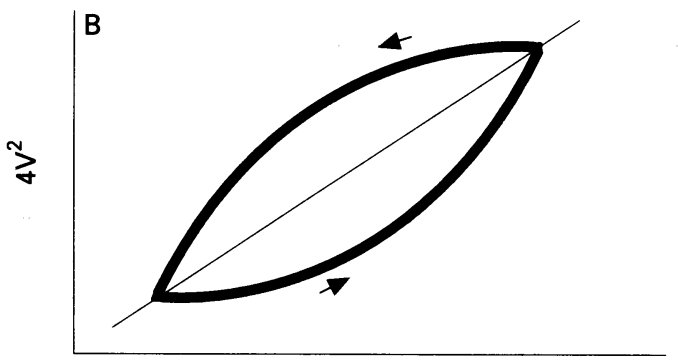

Left ventricular pressure

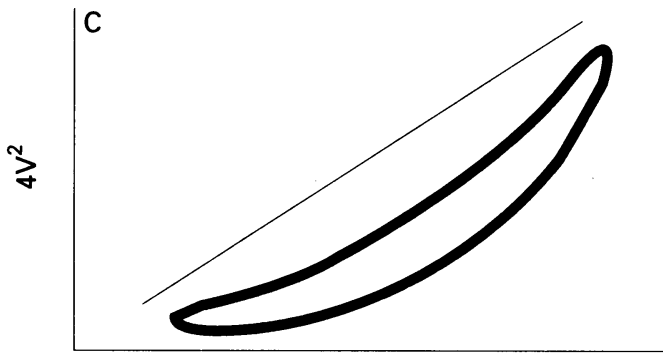

Left ventricular pressure

atrium pressure drop from continuous wave Doppler. Mean pulmonary wedge pressure was added to the latter to derive an estimate of peak left ventricular pressure.

(d) Peak rates of pressure rise $(+\mathrm{d} P / \mathrm{d} t)$ and fall $(-\mathrm{d} P / \mathrm{d} t)$.

(e) Pressure at $+\mathrm{d} P / \mathrm{d} t$ and $-\mathrm{d} P / \mathrm{d} t$.

(f) Times from onset of the QRS complex to peak $+\mathrm{d} P / \mathrm{d} t$ and $-\mathrm{d} P / \mathrm{d} t$.

$(g)$ Time from the q wave to peak pressure-that is, when the $\mathrm{d} P / \mathrm{d} t$ curve crosses the baseline in mid-systole.

\section{STATISTICAL ANALYSIS}

All the measurements were made on three to 10 successive cardiac cycles and for every observation individual values of pressure and velocity were taken. They were expressed as mean (SD). A paired Student's $t$ test was used to assess differences between mean values obtained invasively and non-invasively. When there was no consistent difference between the two, root mean square values were used to quantify the differences between individual estimates. Linear regression was performed between invasive and non-invasive estimates from all the individual beats by the method of least squares.

To investigate instantaneous differences between the two methods throughout systole, rather than simply at the peak value, we plotted the reconstructed Doppler signal against the directly recorded left ventricular pressure (fig 2). Such plots demonstrate several possible interrelations between the two pressures. If the two are precisely equivalent throughout systole, then the plot moves along the line of identity during both upstroke and downstroke, and it will have zero area (fig 2A). Poor beam angulation alters the slope, but not the intercept of the relation. The effects of failing to take left atrial pressure into account displace the curve downwards, though the slope is still one. In the presence of haemodynamically severe mitral regurgitation, a late systolic "V" wave also reduces the slope as well as increases the intercept. If the acceleration term in the Bernoulli equation is significant, the plot becomes a loop with a significant area, though it is centred on the line of identity. Reconstructed values are less than directly measured ones during the upstroke because of the work done accelerating the blood and greater during the downstroke (fig 2B) - that is, the loop proceeds in a counter clockwise direction. At peak pressure, when the rate of change of velocity is zero, the two should again be identical, while maximum deviation occurs at the values corresponding to the peak acceleration and deceleration rates. The Bernoulli relationship is valid only for inviscid fluids and the effect of viscosity leads to a more complex relationship (fig 2C). If the regurgitant jet is stable or can be considered at any instant as being so ("quasistable"), then the viscous effects can be described by a discharge coefficient which relates the real flow rate through the orifice to the ideal flow rate, predicted from the pressure drop by the Bernoulli equation. ${ }^{13}$ The discharge coefficient has a value of 1 or less, the exact figure being very sensitive to orifice

Table 1 Clinical data of the subjects

\begin{tabular}{|c|c|c|c|c|c|}
\hline $\begin{array}{l}\text { Case } \\
\text { no }\end{array}$ & $\begin{array}{l}\text { Age } \\
\text { (years) }\end{array}$ & Sex & $\begin{array}{l}\text { Left ventricular } \\
\text { end diastolic } \\
\text { dimension }(\mathrm{cm})\end{array}$ & $\begin{array}{l}\text { Cardiac } \\
\text { rhythm }\end{array}$ & Clinical features \\
\hline $\begin{array}{l}1 \\
2 \\
3 \\
4\end{array}$ & $\begin{array}{l}57 \\
29 \\
72 \\
80\end{array}$ & $\begin{array}{l}\text { Male } \\
\text { Male } \\
\text { Male } \\
\text { Female }\end{array}$ & $\begin{array}{l}4 \cdot 5 \\
6 \cdot 0 \\
4 \cdot 2 \\
4 \cdot 2\end{array}$ & $\begin{array}{l}\text { Sinus } \\
\text { Sinus } \\
\text { Sinus } \\
\text { Sinus }\end{array}$ & $\begin{array}{l}\text { Coronary bypass for left main coronary lesion } \\
\text { Aortic valve replacement for aortic stenosis } \\
\text { Aortic valve replacement for aortic stenosis and regurgitation } \\
\text { Aortic valve replacement for aortic stenosis and coronary bypass } \\
\text { for three vessel disease }\end{array}$ \\
\hline $\begin{array}{l}5 \\
6 \\
7 \\
8\end{array}$ & $\begin{array}{l}48 \\
40 \\
76 \\
72\end{array}$ & $\begin{array}{l}\text { Male } \\
\text { Male } \\
\text { Female } \\
\text { Female }\end{array}$ & $\begin{array}{l}5 \cdot 0 \\
7 \cdot 0 \\
5 \cdot 5 \\
4 \cdot 7\end{array}$ & $\begin{array}{l}\text { Paced } \\
\text { Sinus } \\
\text { Sinus } \\
\text { Sinus }\end{array}$ & $\begin{array}{l}\text { Aortic valve replacement for aortic regurgitation } \\
\text { Aortic valve replacement for degenerated aortic prosthetic valve } \\
\text { Aortic valve replacement for aortic stenosis } \\
\text { Aortic valve replacement for aortic stenosis and coronary bypass } \\
\text { for three vessel disease }\end{array}$ \\
\hline 9 & 73 & Female & $3 \cdot 6$ & Sinus & Aortic valve replacement for aortic stenosis \\
\hline
\end{tabular}


Table 2 Individual values of time intervals measured by the two methods (mean (SD))

\begin{tabular}{|c|c|c|c|c|c|}
\hline $\begin{array}{l}\text { Case } \\
\text { no }\end{array}$ & $\begin{array}{l}\text { Cardiac } \\
\text { beats }\end{array}$ & $\begin{array}{l}Q \text { to onset } \\
\text { (ms) }\end{array}$ & $\underset{(m s)}{Q t o}+d P / d t$ & $\underset{(m s)}{Q \text { to }} P_{\max }$ & $\underset{(m s)}{Q t o-d P / d t}$ \\
\hline 1 & 9 & \multirow{25}{*}{$\begin{array}{c}60(6 \cdot 0) \\
54(4 \cdot 0) \\
60(7 \cdot 0) \\
56(5 \cdot 0) \\
46(4 \cdot 0) \\
44(3 \cdot 0) \\
47(3 \cdot 0) \\
43(3 \cdot 0) \\
124(28) \\
122(25) \\
121(29) \\
120(28) \\
56(25) \\
55(25) \\
45(4 \cdot 0) \\
46(3 \cdot 0) \\
62(7 \cdot 5) \\
62(8 \cdot 0) \\
53(2 \cdot 5) \\
50(2 \cdot 0) \\
56(6 \cdot 0) \\
55(5 \cdot 5) \\
52(4 \cdot 0) \\
49(5 \cdot 5) \\
67(30) \\
64(30)\end{array}$} & \multirow{25}{*}{$\begin{aligned} 130(15) \\
120(5 \cdot 0) \\
115(25) \\
120(7 \cdot 0) \\
100(9 \cdot 5) \\
110(15) \\
90(10) \\
100(15) \\
175(35) \\
180(35) \\
185(30) \\
185(30) \\
110(30) \\
125(25) \\
105(20) \\
100(15) \\
125(20) \\
123(20) \\
115(20) \\
120(25) \\
125(20) \\
130(20) \\
105(25) \\
100(20) \\
125(35) \\
130(35)\end{aligned}$} & \multirow{25}{*}{$\begin{array}{l}340(20) \\
340(10) \\
245(40) \\
245(35) \\
235(15) \\
225(15) \\
215(25) \\
200(20) \\
280(30) \\
280(35) \\
285(30) \\
290(35) \\
235(25) \\
255(35) \\
245(20) \\
255(15) \\
260(20) \\
235(12) \\
260(10) \\
280(20) \\
305(15) \\
300(15) \\
265(20) \\
275(20) \\
267(40) \\
270(40)\end{array}$} & \multirow{25}{*}{$\begin{array}{l}412(10) \\
415(6 \cdot 0) \\
375(13) \\
375(15) \\
360(10) \\
355(15) \\
350(20) \\
355(15) \\
400(20) \\
400(20) \\
375(30) \\
390(30) \\
350(20) \\
350(20) \\
405(20) \\
390(10) \\
385(15) \\
385(15) \\
395(12) \\
395(10) \\
400(10) \\
400(15) \\
435(35) \\
425(20) \\
389(30) \\
387(28)\end{array}$} \\
\hline 2 & 9 & & & & \\
\hline & & & & & \\
\hline $3 \cdot 1$ & 10 & & & & \\
\hline & & & & & \\
\hline $3 \cdot 2$ & 3 & & & & \\
\hline & & & & & \\
\hline $4 \cdot 1$ & 10 & & & & \\
\hline & & & & & \\
\hline $4 \cdot 2$ & 10 & & & & \\
\hline & & & & & \\
\hline 5 & 10 & & & & \\
\hline & & & & & \\
\hline $6 \cdot 1$ & 9 & & & & \\
\hline & & & & & \\
\hline $6 \cdot 2$ & 9 & & & & \\
\hline & & & & & \\
\hline 7 & 6 & & & & \\
\hline & & & & & \\
\hline 8 & 9 & & & & \\
\hline & & & & & \\
\hline 9 & 10 & & & & \\
\hline & & & & & \\
\hline Total & 104 & & & & \\
\hline & & & & & \\
\hline
\end{tabular}

Values in upper rows are derived from Doppler; those in lower rows from directly measured left ventricular pressure.

$P$, pressure; $P$ max, peak left ventricular pressure.

geometry. In addition, mitral regurgitant flow is pulsatile, so that orifice geometry might vary during the cardiac cycle. This would further complicate the relation between the two.

\section{Results}

\section{GENERAL}

Some 104 cardiac cycles of the nine patients were analysed. Table 1 gives clinical data and tables 2 and 3 measurements from individual patients.

TIME COURSE OF LEFT VENTRICULAR SYSTOLE There were no consistent differences between directly measured and reconstructed pressures in the time intervals from $\mathrm{Q}$ to $+\mathrm{d} P / \mathrm{d} t$
(125 (35) $v 130$ (35) $\mathrm{ms}$ ) and from $\mathrm{Q}$ to $-\mathrm{d} P / \mathrm{d} t(389$ (30) $v 387(28) \mathrm{ms}$ ) or from $\mathrm{Q}$ to maximum pressure $(267(40) v 270$ (40) $\mathrm{ms}$ ), all $\mathrm{P}=\mathrm{NS}$ ) (table 2 ). The time from $\mathrm{Q}$ to the onset of pressure rise, however, did show a small but consistent difference (67 (30) $v$ (64 (30) ms, $P<0.01)$. The root mean square of the differences of these intervals between the two techniques were $12,15,9$ and $3.5 \mathrm{~ms}$, respectively. The duration of total left ventricular systole measured by the two methods was effectively identical (404 (50) $v$ 408 (50) ms, $P<0.01$ ), though again, the small difference was consistent enough to be statistically significant.

\section{LEFT VENTRICULAR PRESSURE AND ITS RATES OF CHANGE}

The peak left ventricular pressure measured by the high fidelity micromanometer ranged from 72 to $150 \mathrm{~mm} \mathrm{Hg}$, the maximal pressure drop from the left ventricle to the left atrium derived from Doppler signals of mitral regurgitation was $45-100 \mathrm{~mm} \mathrm{Hg}$, and the mean (SD) left atrial pressure 9-24 (14 (4)) $\mathrm{mm}$ $\mathrm{Hg}$. Thus, the calculated peak pressure drop (LVPd) between the left ventricle and the left atrium significantly underestimated left ventricular pressure (LVP) (70 (11) $v 105$ (15) $\mathrm{mm} \mathrm{Hg}), \mathrm{P}<0.01$ ) even if left atrial pressure was taken into account. The values obtained by the two methods correlated significantly $(r=0.67, \mathrm{P}<0.01)$. The linear regression equation of the two is:

$$
\mathrm{LVP}=0.90 \mathrm{LVPd}+40(\mathrm{~mm} \mathrm{Hg})
$$

where the slope $(0.9(0.1))$ is significantly different from $1.0(P<0.01)$ and the intercept $(40(5 \cdot 5))$ differs from zero $(P<0.001)$.

Values of pressure measured at $+\mathrm{d} P / \mathrm{d} t$ (26 (6.5) v 53 (10) $\mathrm{mm} \mathrm{Hg}, \mathrm{P}<0.01$ ) and $-\mathrm{d} P / \mathrm{d} t(30(8.0) v 60(10) \mathrm{mm} \mathrm{Hg}, \mathrm{P}<$ 0.01 ) by the Doppler method were only half of those measured by catheter (table 3 ).

Table 3 Individual values of pressure measured by the two methods (mean (SD))

\begin{tabular}{|c|c|c|c|c|c|c|c|}
\hline $\begin{array}{l}\text { Case } \\
\text { no }\end{array}$ & $\begin{array}{l}\text { Mean PWP } \\
(m m \mathrm{Hg})\end{array}$ & $\begin{array}{l}S B P \\
(m m H g)\end{array}$ & $\begin{array}{c}+d P / d t \\
(m m H g / s)\end{array}$ & $\begin{array}{l}P \max \\
(\operatorname{mm} \mathrm{Hg})\end{array}$ & $\begin{array}{l}-d P / d t \\
(m m H g / s)\end{array}$ & $\begin{array}{l}P a t+d P / d t \\
(m m H g)\end{array}$ & $\begin{array}{l}P a t-d P / d t \\
(m m \mathrm{Hg})\end{array}$ \\
\hline 1 & 11 & 114 & $\begin{array}{ll}490 & (60) \\
695 & (25)\end{array}$ & $\begin{array}{r}65(5 \cdot 0) \\
100(5 \cdot 0)\end{array}$ & $\begin{array}{r}730(60) \\
1000(40)\end{array}$ & $\begin{array}{l}18(3 \cdot 5) \\
49(5 \cdot 0)\end{array}$ & $\begin{array}{l}37(6 \cdot 5) \\
68(8 \cdot 0)\end{array}$ \\
\hline 2 & 14 & 97 & $\begin{array}{l}740(165) \\
850(70)\end{array}$ & $\begin{array}{r}75(8 \cdot 0) \\
110(4 \cdot 0)\end{array}$ & $\begin{array}{l}620 \\
825 \quad(65) \\
\end{array}$ & $\begin{array}{l}30(6 \cdot 0) \\
58(9 \cdot 0)\end{array}$ & $\begin{array}{l}31(6 \cdot 0) \\
56(4 \cdot 0)\end{array}$ \\
\hline $3 \cdot 1$ & 10 & 109 & $\begin{array}{r}825(130) \\
1040(155)\end{array}$ & $\begin{array}{r}76(5 \cdot 0) \\
106(4 \cdot 0)\end{array}$ & $\begin{array}{l}695(105) \\
960(105)\end{array}$ & $\begin{array}{l}28(6.5) \\
55(12)\end{array}$ & $\begin{array}{l}32(7 \cdot 0) \\
56(7 \cdot 0)\end{array}$ \\
\hline $3 \cdot 2$ & 11 & 113 & $\begin{array}{r}895(80) \\
1085(30)\end{array}$ & $\begin{array}{r}80(2 \cdot 0) \\
105(1.5)\end{array}$ & $\begin{array}{l}600(85) \\
835(110)\end{array}$ & $\begin{array}{l}29(1 \cdot 5) \\
57(7.5)\end{array}$ & $\begin{array}{l}30(4 \cdot 0) \\
50(7 \cdot 0)\end{array}$ \\
\hline $4 \cdot 1$ & 18 & 116 & $\begin{array}{l}715(40) \\
775(115)\end{array}$ & $\begin{array}{r}73(8 \cdot 0) \\
105(4 \cdot 0)\end{array}$ & $\begin{array}{ll}590 & (45) \\
840 & (70)\end{array}$ & $\begin{array}{l}29(5 \cdot 0) \\
60(4 \cdot 5)\end{array}$ & $\begin{array}{l}25(4 \cdot 5) \\
55(8 \cdot 0)\end{array}$ \\
\hline $4 \cdot 2$ & 24 & 117 & $\begin{array}{l}705(130) \\
800(70)\end{array}$ & $\begin{array}{r}70(8 \cdot 0) \\
113(7 \cdot 0)\end{array}$ & $\begin{array}{l}630(70) \\
845(105)\end{array}$ & $\begin{array}{l}30(6 \cdot 5) \\
67(4 \cdot 0)\end{array}$ & $\begin{array}{l}34(6 \cdot 5) \\
70(6 \cdot 5)\end{array}$ \\
\hline 5 & 19 & 107 & $\begin{array}{ll}550 & (60) \\
555 & (70)\end{array}$ & $\begin{array}{l}53(8 \cdot 0) \\
90(9 \cdot 0)\end{array}$ & $\begin{array}{ll}450 & (95) \\
730 & (80)\end{array}$ & $\begin{array}{l}21(5 \cdot 0) \\
46(7 \cdot 0)\end{array}$ & $\begin{array}{l}24(4 \cdot 0) \\
61(4 \cdot 0)\end{array}$ \\
\hline $6 \cdot 1$ & 12 & 95 & $\begin{array}{l}600(140) \\
730(75)\end{array}$ & $\begin{array}{l}57(7 \cdot 0) \\
82(7 \cdot 0)\end{array}$ & $\begin{array}{ll}425 & (80) \\
690 & (60)\end{array}$ & $\begin{array}{l}22(4 \cdot 5) \\
42(8 \cdot 5)\end{array}$ & $\begin{array}{l}23(2 \cdot 0) \\
47(3 \cdot 0)\end{array}$ \\
\hline $6 \cdot 2$ & 12 & 99 & $\begin{array}{ll}525 & (95) \\
825 & (35)\end{array}$ & $\begin{array}{l}55(5.0) \\
85(3.0)\end{array}$ & $\begin{array}{ll}550 & (75) \\
675 & (60)\end{array}$ & $\begin{array}{l}20(2 \cdot 0) \\
46(7 \cdot 0)\end{array}$ & $\begin{array}{l}24(2 \cdot 0) \\
46(3 \cdot 0)\end{array}$ \\
\hline 7 & 12 & 95 & $\begin{array}{ll}680 & (95) \\
855 & (30)\end{array}$ & $\begin{array}{l}70(5 \cdot 0) \\
122(20)\end{array}$ & $\begin{array}{r}630(90) \\
1070(205)\end{array}$ & $\begin{array}{l}30(7 \cdot 0) \\
56(8 \cdot 5)\end{array}$ & $\begin{array}{l}34(7 \cdot 0) \\
65(14)\end{array}$ \\
\hline 8 & 15 & 125 & $\begin{array}{ll}640 & (65) \\
930 & (55)\end{array}$ & $\begin{array}{r}80(5 \cdot 0) \\
130(5 \cdot 0)\end{array}$ & $\begin{array}{r}885(90) \\
1095(90)\end{array}$ & $\begin{array}{l}25(7 \cdot 0) \\
62(9 \cdot 0)\end{array}$ & $\begin{array}{l}39(4 \cdot 5) \\
78(10)\end{array}$ \\
\hline 9 & 9 & 106 & $\begin{array}{l}825(120) \\
840(95)\end{array}$ & $\begin{array}{l}79(9 \cdot 5) \\
95(15)\end{array}$ & $\begin{array}{l}510(85) \\
675(160)\end{array}$ & $\begin{array}{l}28(5 \cdot 5) \\
46(12)\end{array}$ & $\begin{array}{l}38(6 \cdot 0) \\
60(12)\end{array}$ \\
\hline Total & $14(4 \cdot 0)$ & $108(9 \cdot 0)$ & $\begin{array}{l}675(155) \\
815(155)\end{array}$ & $\begin{array}{r}70(11) \\
105(15)\end{array}$ & $\begin{array}{l}610(145) \\
845(175)\end{array}$ & $\begin{array}{l}26(6 \cdot 5) \\
53(10)\end{array}$ & $\begin{array}{l}30(8 \cdot 0) \\
60(10)\end{array}$ \\
\hline
\end{tabular}


Figure 3 Representative plots of directly recorded left ventricular pressure and pressure drop from the left ventricle (LV) to the left atrium (LA) reconstructed with continuous wave Doppler of functional mitral regurgitation. The instantaneous differences between the two are demonstrated (see text). $(A)$ and $(B)$ are more common than $(C)$ and (D).
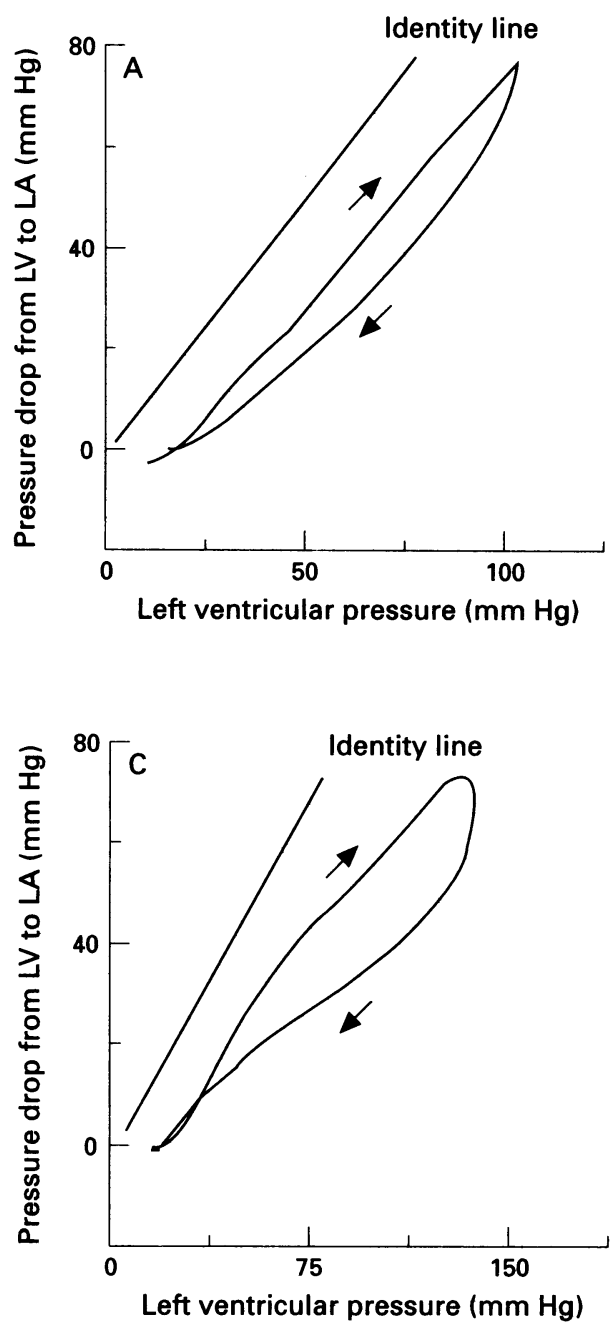

The rates of increase (675 (155) $v 815$ (155) $\mathrm{mm} \mathrm{Hg} / \mathrm{s}, \mathrm{P}<0.01)$ and fall (610 (145) $v 845$ (175) $\mathrm{mm} \mathrm{Hg}, \mathrm{P}<0.01$ ) were also significantly underestimated by Doppler compared with those directly derived from left ventricular pressure. Though there were statistically significant correlations between the values obtained by the two methods $(\mathrm{d} P / \mathrm{d} t, r=0.55,-\mathrm{d} P / \mathrm{d} t, r=0.71$, both $\mathrm{P}<$ 0.01 ), correlation coefficients were low. Full results of regression analysis are given in table 4 .

SCALING EFFECTS ON PEAK RATES OF PRESSURE CHANGE

If pressure itself is underestimated, the corresponding values of peak rates of change will necessarily be reduced. In order to investigate the possibility that the large discrepancies between directly and Doppler-derived esti-

Table 4 Regression analysis of peak rates of pressure change

\begin{tabular}{llllll}
\hline Equation & \multicolumn{2}{l}{$S D$} & & \\
\cline { 3 - 4 } & Slope & Intercept & Sy.x & $r^{2}$ \\
\hline $\mathrm{d} P / \mathrm{d} t(\mathrm{~mm} \mathrm{Hg} / \mathrm{s})=0.53 \times(\mathrm{d} P / \mathrm{d} t \mathrm{~m})+460$ & 0.08 & 57 & 130 & 0.28 \\
$-\mathrm{d} P / \mathrm{d} t(\mathrm{~mm} \mathrm{Hg} / \mathrm{s})=0.84 \times(-\mathrm{d} P / \mathrm{d} t \mathrm{~m})+340$ & 0.08 & 51 & 125 & 0.50 \\
$\mathrm{~d} P / \mathrm{d} t(\mathrm{~mm} \mathrm{Hg} / \mathrm{s})=0.72 \times(\mathrm{d} P / \mathrm{d} t \mathrm{~m} \mathrm{C})+165$ & 0.09 & 90 & 55 & 0.85 \\
$-\mathrm{dP} / \mathrm{dt}(\mathrm{mm} \mathrm{Hg} / \mathrm{s})=0.67 \times(-\mathrm{dP} / \mathrm{dtm} \mathrm{C})+310$ & 0.10 & 90 & 70 & 0.80 \\
\hline
\end{tabular}

$\mathrm{d} P / \mathrm{d} t \mathrm{~m}$, value derived from continuous wave Doppler of mitral regurgitation; $\mathrm{d} P / \mathrm{d} t \mathrm{~m} C$ corrected value by scaling effect; Sy.x, standard error of the estimate of $y$ on $x$.
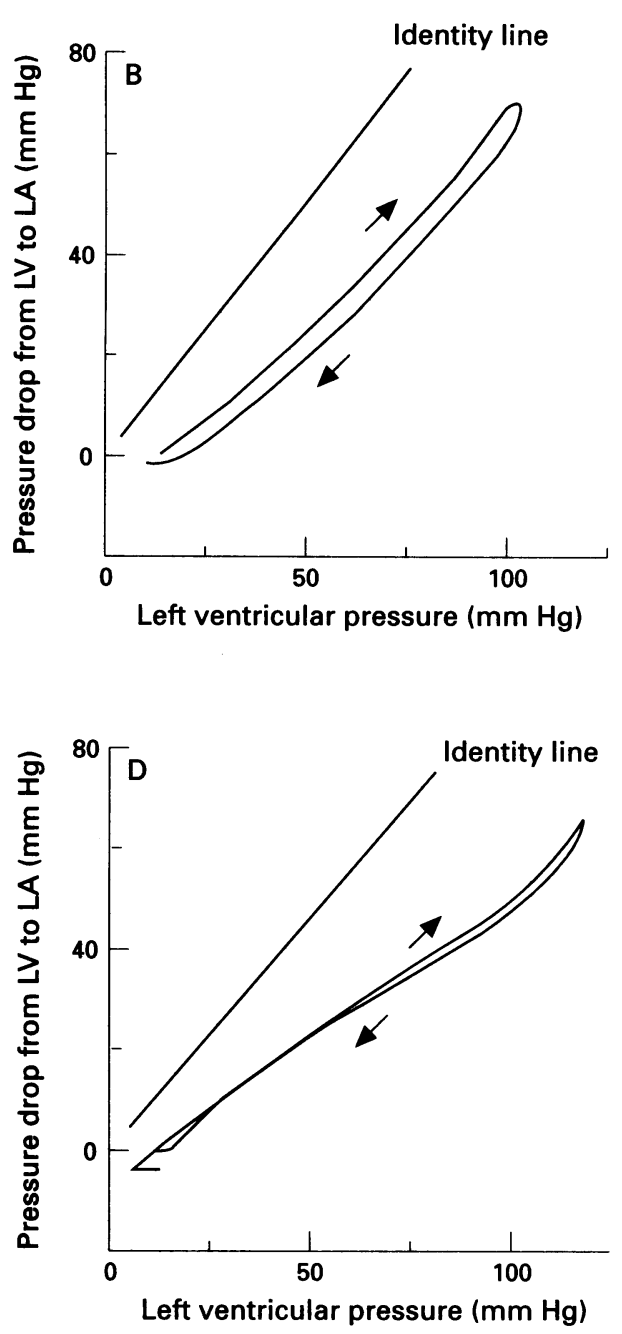

mates of peak positive and negative $\mathrm{d} P / \mathrm{d} t$ occurred on this basis, we scaled Dopplerderived values for peak rates of change by the ratio of the simultaneous values of directly measured and Doppler-derived pressure plus mean indirect left atrial pressure. When corrected in this way, the modified Dopplerderived $+\mathrm{d} P / \mathrm{d} t$ overestimated the directly measured values by a mean of $95 \mathrm{~mm} \mathrm{Hg} / \mathrm{s}(\mathbf{P}$ $<0.01$ ), while mean values of peak $-\mathrm{d} P / \mathrm{d} t$ did not differ significantly. Correlation between Doppler-derived and directly measured values became very much closer (table 4), with the SE of the estimate falling to approximately half. The slopes of both relations, however, remained significantly less than 1 , and intercepts greater than zero.

\section{CONTINUOUS ESTIMATION OF THE}

INSTANTANEOUS DIFFERENCES IN PRESSURE BETWEEN THE TWO METHODS

Figure 3 shows specimen plots of the relation between the directly recorded and reconstructed left ventricular pressures. All the plots had the following characteristics: they had a finite area; all fell below the line of identity-that is, reconstructed pressure was always less than directly measured pressure; the trajectories of the loops were all non-linear, so that the relative degree of underestimation of the derived pressure often fell as the pressure rose. Figure 4 shows the per cent 
Figure 4 Directly measured left ventricular pressure against relative underestimation by Doppler-derived value (reconstructed pressure + mean left atrial pressure) from a representative patient. Note that the degree of underestimation is greater at lower levels of directly measured pressure.

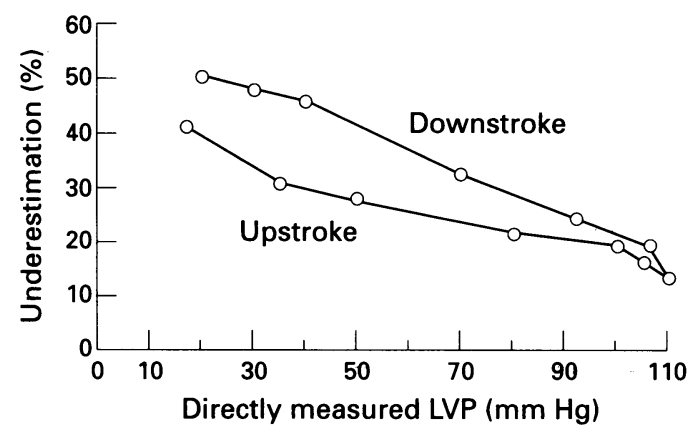

underestimation of the reconstructed pressure as a function of directly measured pressure from a representative case and, finally, the majority (80 of $104,77 \%$ ) was inscribed in a clockwise direction, indicating that the degree of underestimation was less during the upstroke.

\section{Discussion}

Our original aim in this study was to compare the time relations between directly measured and reconstructed pressure traces. The reason for our interest is the potential value of ventricular pressure as a marker of the time course of mechanical systole. In patients with left bundle branch block, for example, the interval from the q wave of the electrocardiogram to the onset of mitral regurgitation is 50 ms compared with $75 \mathrm{~ms}$ in those without such interference. ${ }^{14}$ Similarly, the overall duration of regurgitation in left bundle branch block is $480 \mathrm{~ms}$, but $415 \mathrm{~ms}$ in right ventricular pacing. ${ }^{15}$ Compared with values such as these, discrepancies between directly measured and reconstructed ventricular pressure pulses were small, ranging from $3 \mathrm{~ms}$ for electromechanical delay to $15 \mathrm{~ms}$ for the timing of peak negative $\mathrm{d} P / \mathrm{d} t$. Clearly, therefore, the non-invasive approach is adequate for such studies.

The time differences between the two methods, though small, were consistent enough to be statistically significant. We do not believe they are clinically significant discrepancies in the range of 5-10 ms can easily be explained by technical considerations. The directly measured pressure pulse was smoothed with a resistive-capacitative network $(200 \mathrm{~Hz})$, which is likely to have introduced a delay of 2-4 ms. The continuous wave Doppler system that we used derived the Doppler spectra by fast Fourier transform. This process requires a finite time, and at the frequencies used is likely to have been of the order of $5 \mathrm{~ms}$. It is not possible to measure zero flow by Doppler, and thus the apparent onset of flow is delayed. We used a process of visual extrapolation to derive this information, but again errors of the order of a few milliseconds are likely to have been introduced. Therefore, the magnitude of the discrepancies in timing between the two methods can be readily explained on technical grounds from the characteristics of the equipment that we used.
There are numerous experimental and clinical reports of extremely close agreement between directly measured and reconstructed pressures, with slopes indistinguishable from 1 and intercepts from zero, and overall correlation coefficients of 0.95 and above. ${ }^{7-11} \mathrm{We}$ were not able to confirm these findings, but found that the values from the reconstructed pressure were consistently lower than those from the directly measured one. The regression equation relating Doppler derived to directly measured maximum pressure was unusual, not only was the slope significantly less than 1 , but there was an intercept of 40 $\mathrm{mm} \mathrm{Hg}$, very much larger than the mean value of indirect left atrial pressure. If the same relation was to apply to the whole pressure trace, this finding would clearly be incompatible with our observations on timing of the onset and duration of ventricular pressure. Further evidence that the relation varied over the course of systole came from the observation that discrepancies between Doppler derived and directly measured pressure were greater at the time of peak positive and negative rates of pressure rise. It therefore seemed useful not only to compare peak values, as has been done in previous studies, but to undertake a more extensive examination of the interrelations between the two methods.

It was in order to do this that we constructed loops by plotting directly measured against reconstructed pressures throughout the cardiac cycle. This approach was designed to investigate the various components of the full rather than the simplified Bernoulli equation. It was therefore possible to demonstrate that the disagreement was not because of the acceleration or deceleration terms. Rather, there was underestimation by Doppler throughout systole. This reached a minimum at the time of peak pressure, and its relative extent increased progressively as pressure fell. In addition, the curves had finite area, with the discrepancy being greater during the downstroke in most cardiac cycles. Both trajectories were non-linear. The extent and characteristic nature of these discrepancies allow a number of possible explanations to be excluded. Inappropriate ultrasound beam angulation would not explain their extent, the presence of a large positive intercept, or the changing relation between the two during a single cardiac cycle. The pulmonary wedge pressure was much too low for a high left atrial pressure to have been the basis for the large intercept of $40 \mathrm{~mm} \mathrm{Hg}$. If a "V" wave had been present it would have increased during ventricular ejection, while the discrepancy was larger during isovolumic contraction than it was during late systole. Effectively, therefore, the velocities of retrograde flow were consistently less than those predicted from the pressure drop across the valve. Such discrepancies are well recognised in fluid dynamics, and are quantified in terms of the discharge coefficient. ${ }^{16}$ In real systems, dealing with a fluid with viscosity, discharge coefficients are always less than 1 and may be less than $0 \cdot 5$. A value greater than 1 would be incompatible 
with the law of conservation of energy. The coefficient is determined by the precise geometry of the orifice though in a complex way. It is, unfortunately, not possible to make useful deductions about geometry from a measured discharge coefficient. Viewed in this light, our observations can be readily explained. They would suggest, in addition, that geometry of the effective orifice limiting functional mitral regurgitation varies throughout systole. Previous evidence for this idea, based on simple measures of valve resistance, has already been reported by Nishigami et al. ${ }^{17}$

The low correlation between Doppler derived and directly measured values of peak rates of pressure change led to SEs of the estimate that were unacceptably high for clinical use in individual patients. However, these discrepancies were largely the result of the variable underestimation of pressure itself. Once values for rates of change were appropriately scaled, correlation coefficients increased and SEs were halved. These inter relations may imply that Doppler can be used to estimate relative rates of pressure change $(\mathrm{d} P / \mathrm{d} t / P)$, and by implication time constants of pressure rise or fall if the curve is exponential; absolute values though appear to be much less reliable. Whether the calibration curve between directly measured and Doppler-derived pressures remains constant in individual cases we have yet to determine; only if it does so would it be possible to rely on within patient changes in absolute values of peak rates of pressure change with drugs or other manoeuvres.

Our study clearly had limitations. We used the transoesophageal approach to give optimal images in the immediate postoperative period, but have no direct information as to whether beam orientation defined was optimal. A biplane probe was used, however, and jet orientation defined in both planes by colour flow. In addition, a recent study in patients with mitral stenosis has demonstrated identical peak velocities measured by the transthoracic and transoesophageal approaches using similar methods. ${ }^{18}$ The majority of patients were undergoing aortic valve replacement, and it is possible that the mechanism underlying mitral regurgitation differed from that seen in patients with dilated left ventricular cavity. There was a small (4 French gauge) catheter across the mitral valve in all, but there was no catheter artefact on the Doppler trace itself, so we do not think the regurgitation was catheter induced. It is possible that the regurgitant jet angle may have varied during systole. This was not obvious on colour flow, and when the jet angle does change significantly the continuous Doppler signal of mitral regurgitation is usually incomplete. It would clearly have been preferable to have measured left atrial pressure directly with a second micromanometer, but this would have involved another left-sided catheter, for which we did not have ethical clearance. We believe, however, that mean wedge pressure provides a closer approximation to left atrial than simply adding a fixed number to the value derived by
Doppler. The onset and termination of the Doppler signal were clear, and could readily be defined by linear extrapolation to the baseline. We used established criteria to define landmarks on the directly measured pressure pulse. ${ }^{19}$

The onset of the rapid upstroke after the A wave was simple to measure. At the end of systole, we recorded the time when the falling pressure reached a value corresponding to the end diastolic. This is likely to have corresponded to the time of mitral valve opening, rather than the true end of ventricular mechanical activity, which decays exponentially and becomes ill defined once ventricular filling starts. In retrospect, this convention measures the time interval over which left ventricular pressure exceeds that in the left atrium, and would therefore be compatible with the two methods agreeing closely.

We believe it is possible to explain many of the differences between our results and those of some previous studies. When observations are not made simultaneously, or when fluid filled manometers are used, ${ }^{910}$ no further explanation need be sought. Similarly, when maximum values, rather than individual beatto-beat comparisons, are made ${ }^{10}$ the possibility of overestimation is likely. Though our findings differ from previous studies in humans in that they were determined during the perioperative period, this does not seem a valid reason for the discrepancy. If our ideas are correct, orifice geometry is important. The characteristics of functional valvar regurgitation are therefore potentially different from those of organic disease, particularly when caused by cusp perforation where orifice size is likely to be more fixed. This applies also to experimental studies in which a small grommet is inserted into a mitral valve cusp. ${ }^{7}$ Indeed, such geometry has a very high discharge coefficient. ${ }^{16}$ In two studies, one experimental ${ }^{7}$ and one clinical, ${ }^{20}$ representative pressure traces were reproduced, which were suitable for processing by our methods. When we did so, we demonstrated both to have an identical pattern with a loop inscribed in a clockwise direction and consistent underestimation at lower pressure. Loop area was smaller in the experimental study compared with most of those that we recorded in humans.

In summary, our results confirm the eminent suitability of the continuous wave Doppler trace of functional mitral regurgitation for studying the timing of mechanical events in the left ventricle. In addition, estimates of normalised peak rates of pressure change, and by implication time constants of pressure rise or fall are also likely to be reliable. Estimates of the absolute pressure drop calculated from the simplified Bernoulli equation are less satisfactory, the calibration curve between the two differing between patients and varying with pressure itself throughout systole, probably as the result of changing orifice geometry. These results underline the complex nature of the physical determinants of functional mitral regurgitation, and 
therefore of factors that must be taken into account when deductions are made from it. It is a subject that would seem to repay further investigation.

We thank Dr K Parker, Physiological Flow Study Group, Imperial College, London, and Mr RB Logan-Sinclair, Medical Engineering Department, Royal Brompton Hospital, London, for their help in preparing this manuscript. HBX and XYJ are both supported by the Royal Brompton Hospital Special Cardiac Fund.

1 Wiggers CJ. Studies on the consecutive phases of the cardiac cycle. I. The duration of the consecutive phases of the cardiac cycle and the criteria for their precise determination. Am F Physiol 1921;56:415-38.

2 Wiggers CJ. The muscular reactions of the mammalian ventricles to artificial surface stimuli. Am $\mathcal{F}$ Physiol 1925; 73:346-78.

3 Wiggers CJ. Are ventricular conduction changes important in dynamics of ventricular contraction? Am $\mathcal{F}$ Physiol 1926;74:12-30.

4 Braunwald E, Morrow AG. Sequence of ventricular contraction in human bundle branch block. A study based on simultaneous catheterization of both ventricles. $A m \mathcal{F}$ Med 1957;23:205-11.

5 Braunwald E, Donoso E, Sapin SO, Grishman A. Right bundle branch block. Hemodynamic, vectorcardiobundle branch block. Hemodynamic, vectorcardiographic and electroc

6 Mason DT, Braunwald E, Covell JW, Sonnenblick EH, Ross J Jr. Assessment of cardiac contractility. The relation between the rate of pressure rise and ventricular pressure during isovolumic systole. Circulation 1971;44: 47-58.

7 Chen C, Rodriguez L, Guerrero JL, et al. Noninvasive estimation of the instantaneous first derivative of left ventricular pressure using continuous-wave Doppler echocardiography. Circulation 1991;83:2101-10.

8 Chen C, Rodriguez L, Levine RA, Weyman AE, Thomas JD. Noninvasive measurement of the time constant of left ventricular relaxation using the continuous-wave
Doppler velocity profile of mitral regurgitation. Circulation 1992;86:272-8.

9 Nishimura RA, Tajik AJ. Determination of left-sided pressure gradients by utilizing Doppler aortic and mitral regurgitant signals: validation by simultaneous dua catheter and Doppler studies. F Am Coll Cardiol 1988. 11:317-32.

10 Bargiggia GS, Bertucci C, Recusani F, et al. A new method for estimating left ventricular $\mathrm{dP} / \mathrm{dt}$ by continuous wave Doppler-echocardiography. Validation studies at cardiac coppler-echocardiography. Validation studies

11 Chung N, Nishimura RA, Holmes DR, Tajik AJ Measurement of left ventricular dP/dt by simultaneous Measurement of left ventricular $\mathrm{dP} / \mathrm{dt}$ by simultaneous $\mathfrak{f}$ Am Soc Echocardiogr 1992;5:147-52.

12 Jin XY, Brecker SJ, Carey J, et al. Comparison of left ventricular performance immediately after aortic valve replacement using crystalloid or blood cardioplegia. $\mathrm{Br}$ Heart f 1994;71(suppl):75 (Abstract)

13 Milnor WR. Steady flow. In: Milnor WR, ed. Hemodynamics. 2nd ed. Baltimore: Williams \& Wilkins, 1989:11-50.

14 Xiao HB, Lee CH, Gibson DG. Effect of left bundle branch block on diastolic function in dilated cardiomyopathy. Br Heart f 1991;66:443-7.

15 Xiao HB, Brecker SJD, Gibson DG. Differing effects of right ventricular pacing and left bundle branch block on left ventricular function. Br Heart $f$ 1993;69: 166-73.

16 Vennard JK, Street RL. Elementary Fluid Mechanics. 5th ed. New York: John Wiley \& Sons, 1976.

17 Nishigami K, Yoshikawa J, Yoshida K, et al. Time analysis of mitral regurgitant orifice area: a clinical study using of mitral regurgitant orifice area: a clinical study using Doppler color proximal isovelocity

18 Stoddard MF, Prince CR, Tuman WL, Wagner SG. Angle of incidence does not affect accuracy of mitral stenosis area calculation by pressure half-time: application to Doppler transesophageal echocardiography. Am Heart $\mathcal{f}$ 1994;127:1562-72.

19 Gleason WL, Braunwald E. Studies on the first derivative of the ventricular pressure pulse in man. $\mathcal{F}$ Clin Invest 1962 41:80-91.

20 Nishimura RA, Schartz RS, Tajik AJ, Holmes DR Jr. Noninvasive measurement of rate of left ventricular relaxation by Doppler echocardiography. Validation with simultaneous cardiac catheterization. Circulation 1993;88:146-55. 